\title{
LA VÍA CHILENA AL "SOBRE” CAPITALISMO AGRARIO
}

José Bengoa Cabello 


\section{JOSÉ BENGOA CABELLO}

Es Licenciado en Filosofía y se ha especializado en temas de historia y cultura. Fue miembro del Centro de Estudios Socioeconómicos de la Facultad de Economía de la Universidad de Chile y fundó la Escuela de Antropología de la Academia de Humanismo Cristiano, universidad de la cual fue rector en dos oportunidades. Actualmente se desempeña como profesor en dicha Escuela. Es autor, entre muchas otras obras, de Historia del pueblo mapuche (1985), Historia rural de Chile central (2015) y Reforma Agraria y revuelta campesina, editado en 2016 por LOM. 


\section{LA VÍA CHILENA AL “SOBRE” CAPITALISMO AGRARIO}

"Marx comprendió que las economías de mercado modernas abandonadas a ellas mismas producen desigualdades obscenas".

Louis Menand. New Yorker, octubre 2016

Suena quizá demasiado exagerado el título. Sin embargo, al conmemorarse los 50 años de la dictación de la ley de Reforma Agraria, no cabe mucha duda de que el tránsito de la sociedad chilena desde una situación semi capitalista, que algunos denominaban con razón feudal, a una de un capitalismo pleno, globalizado, monopólico y quizás salvaje, que nos atrevemos a ponerle el mote de "sobre", tuvo que ver con este proceso. La Reforma Agraria abrió las transformaciones más importantes que han ocurrido en la historia reciente de Chile; ha sido el proceso histórico social y de carácter estructural de mayor importancia a lo menos en el siglo XX. Las consecuencias políticas son evidentes: fue a causa de que el movimiento popular y político reformista de centro e izquierda realizara estas enormes transformaciones a lo largo y ancho del angosto y conservador país, que sobrevino con especial virulencia el golpe de Estado de 1973. Se trató de revertir, sin éxito, los cambios, y de ponerle una placa mortuoria al movimiento campesino y en general popular. No se logró totalmente a pesar de la cantidad de muerte, desapariciones y violencia.

Es por ello que podemos decir que fue la "Via chilena al capitalismo agrario" y al capitalismo que en plenitud domina la economía y sociedad chilena, un sistema en que el capital no tiene amarras y por ello se le puede denominar de "sobre" capitalismo. No es un asunto menor en la vida de los países o sociedades el modo cómo se transita desde formas productivas, sociales y político culturales ligadas a un sistema capitalista parcial, con evidentes resabios de sistemas feudales, a formas modernas y plenamente capitalistas. Los autores clásicos señalaban que había tres vías: la inglesa, la francesa y la Junker o alemana en Europa; luego se agregó la vía de la colonización europea de ultramar o vía norteamericana. La francesa se había producido en el contexto de la revolución en que los campesinos, apoyados por la burguesía urbana principalmente, destruyeron el sistema feudal. La alemana, en cambio, señalaba que los mismos propietarios feudatarios se habían transformado en "Junkers", esto es, empresarios capitalistas propiamente tales, y es necesario recordar, en militares modernos, el ejército prusiano. En Chile no fue ni la una ni la otra vía, sino una combinación compleja de factores con resultados semejantes, la 
abolición de los resabios feudales, serviles, el latifundio improductivo y las rentas de la tierra a ese sistema asociadas.

\section{LA INSTALACIÓN DEL "SOBRE” CAPITALISMO AGRARIO}

El sistema agro hacendal en Chile duró más allá de lo prudente. Las grandes haciendas y el sistema de inquilinaje, verdadera esclavitud criolla, existieron legalmente hasta el año 1967, en que se dictó la ley de Reforma Agraria en el gobierno del Presidente demócratacristiano Eduardo Frei Montalva, y realmente hasta 1980 aproximadamente, en que terminaron los procesos conjuntos, parte de un mismo plan, de reforma y contrareforma agraria.

La crítica al sistema hacendal es muy antigua en Chile. Sectores católicos ya a fines del siglo antepasado miraban con dolor las condiciones en que vivía el campesinado de las haciendas. El movimiento obrero, Recabarren y el naciente Partido Comunista llaman al reparto de la tierra y a la liquidación del latifundio. Tancredo Pinochet Le Brun, en los días del Centenario de la República, viaja vestido de gañán a la Hacienda Camarico, propiedad de su Excelencia de la República, y en su conocido panfleto le dice: "sus caballos viven en mejores condiciones que sus inquilinos". Marmaduque Grove, fundador del Partido Socialista, imprime un fuerte panfleto llamando a hacer la reforma agraria en los años treinta. El momento clave, sin embargo, fue durante el Frente Popular, en que la Comisión Ministerial así denominada, reunió a hacendados, políticos y dirigentes campesinos como Juan Chacón Corona del Partido Comunista. En ese momento, año 1941, se jugaron las cartas de la historia posterior de Chile. Olavarría Bravo, Ministro del Interior, termina las conversaciones sobre la sindicalización campesina con una orden ministerial. Lo mismo ocurre con la Comisión de Tierras que veía la cuestión de las tierras usurpadas a los mapuches. Se detuvo el proceso dando pie a la industrialización sustitutiva como prioridad y permitiendo que el sistema hacendal perdurara intocado e intocable por dos décadas y media, justamente 25 años más, desde 1941 a 1967. Aquello significó una generación entera de campesinos condenados a la tierra, una generación de patronos rentistas, la mantención de la derecha política, conservadora y liberal, pero también de otros sectores como el agrario laborista y todas las consecuencias que es posible imaginar.

La crítica al sistema hacendal provino crecientemente de todos los sectores, menos de los latifundistas. Los comunistas organizaron a los campesinos federados, como se les decía; los socialistas se introducían en el campo a través de sus líderes y sobre todo caudillos, y finalmente la Iglesia Católica jugará un papel irreemplazable en la demolición latifundiaria. El Obispo de Talca, don Manuel Larraín, y el de 
Santiago, don Raúl Silva Henríquez, ambos de prosapia latifundiaria, romperán la antigua y tradicional alianza entre hacienda e Iglesia. Tal como se ve en todas las casas de hacienda que están pegadas a la Iglesia, estas dos instituciones se debían la una a la otra. Larraín llega a decir que "el latifundio es un pecado", ante la indignación de quienes se habían sentido desde siempre protegidos por el manto eclesiástico. Desde sus inicios la hacienda fue comprendida como un sistema misional, el "encomendado" en evangelizar a los paganos. Por tanto, esa ruptura fue determinante. Fue lo que condujo a que la Democracia Cristiana, y sobre todo Eduardo Frei, pusiera en el centro de su programa la cuestión agraria. Incluso las presiones externas eran tan fuertes que el propio Presidente Alessandri Rodríguez se vio obligado a dictar una ley que, por su falta de eficacia expropiatoria, Mario Palestro la denominó la "reforma del macetero", nombre con que se la conoce hasta hoy.

El año 1964 tanto Eduardo Frei como Salvador Allende le plantearon al país terminar con el latifundio y sobre todo con el inquilinaje, y las condiciones oprobiosas en que vivían los campesinos. Ese debate, junto con la nacionalización o chilenización del cobre, marcaron la década del sesenta y transformaron a Chile. La derecha quedó aislada y aniquilada políticamente entre la elección presidencial y la parlamentaria. El Presidente envió primero al Congreso la modificación de la Constitución que le permitiría expropiar los campos y luego la ley de Reforma Agraria.

Es preciso señalar que la participación campesina en este proceso de elaboración y dictación de la Reforma Agraria fue muy modesta o inexistente. Hasta 1967 las organizaciones campesinas reunían a un poco más de tres mil adherentes en todo el país. A la Federación Campesina e Indígena del Partido Comunista, posteriormente denominada Ranquil, se unía la Unión de Campesinos Cristianos (UCC) que se había fundado al amparo e inspiración del Padre Hurtado y la Asociación Nacional de Organizaciones Campesinas (ANOC), proveniente de los ex estudiantes del Instituto de Educación Rural (IER) de la Iglesia Católica. Eran pequeñas organizaciones, sin duda de la mayor importancia y valor miradas desde el día de hoy. Pero el proceso de elaboración de la ley de reforma estuvo en manos de los técnicos de la Democracia Cristiana y del debate parlamentario en que Salomón Corbalán, por el Partido Socialista, dirigía a técnicos y políticos de ese sector. Quien tuvo quizá la mayor claridad sobre el proceso fue el propio Presidente Frei, quien acuñó la idea de crear 100 mil nuevos pequeños propietarios, una suerte de clase media rural que fuera el sustento social y político de la futura democracia chilena.

Es preciso comprender que las reformas comenzaron el año 1967 y que con ellas se desata una gran "revuelta campesina" a partir del año 1969/70, y sobre todo durante el gobierno del doctor Salvador Allende, quien llevó las cosas en el 
campo ( y en el país) a un punto de no retorno. Luego del golpe de Estado del 11 de septiembre de 1973 continúa el proceso con lo que hemos denominado la "contrarreforma agraria", siendo históricamente un solo período de 10 años de gigantescas transformaciones rurales.

Las consecuencias fueron terribles y paradójicas.

El 11 de septiembre del año 1973 Augusto Pinochet Ugarte da un golpe de Estado y en el campo se produce una masacre de los campesinos alzados. En estos últimos años, décadas después de ocurridos los hechos, recién se comienzan a saber detalles de lo que allí pasó. Patrones de las haciendas, gente de los pueblos junto a "Carabineros", apresaron, torturaron y asesinaron a cientos de campesinos. Fue una represión local, una suerte de "revancha" del latifundio y los sectores subalternos a él ligados, como ha ocurrido en muchas partes del mundo ${ }^{1}$.

Lo segundo que ocurrió fue la contrarreforma agraria, que en vez de retrotraer la situación de la tenencia de la tierra a su estado anterior procedió a la pulverización de la propiedad agrícola en Chile y con ello a producir grandes transformaciones en el campo. De los 10 millones de hectáreas aproximadamente expropiadas, aproximadamente el 25\% (2.5 millones de hectáreas) se les devolvió a los antiguos patronos. Es interesante observar que una gran cantidad de ellos vendió rápidamente el campo por los temores e incertidumbres. Otras dos millones de hectáreas, por lo general de tierras de buena calidad, un 20\% aproximadamente, se le entregó en parcelas a los campesinos de las antiguas haciendas y el resto fue fragmentado y rematado. Se realizaron 1.504 proyectos de parcelación en un número igual de predios o latifundios, lo que equivale casi al 50\% de los predios expropiados. 700 mil hectáreas se les devolvieron como reservas a los antiguos patrones, casi el 10\% se dejó como bienes comunes o "reservas Cora", otro porcentaje no menor fue traspasado al Ejército. Las tierras del "secano costero", esto es, tierras de rulo, fueron rematadas y se privilegiaba a "sociedades campesinas". A pesar de que se formaron algunas, hoy no queda ninguna de ellas. Un fenómeno poco estudiado, pero a nuestro modo de ver muy gravitante en este proceso de pulverización de la propiedad agrícola, de mercantilización rápida de la propiedad territorial, fue el endeudamiento de los antiguos hacendados auto nominados como "empresarios agrícolas". Pinochet llamó a sembrar "hasta las orillas de los caminos" y sus seguidores lo hicieron. Pidieron créditos a los bancos en momentos en que había una inflación aún galopante y tasas de interés usureras. Ante la incredulidad de

1. Ver el ensayo de Javier Rebolledo. A la sombra de los cuervos. Los cómplices civiles de la dictadura. Ceibo Editores. Santiago de Chile. 2015, y José Bengoa. Reforma Agraria y Revuelta Campesina. Seguido de un Homenaje a los campesinos detenidos desaparecidos. Lom Ediciones. Santiago de Chile. 2016. 
quienes creían ser los beneficiarios del golpe de Estado, un ministro de Agricultura de la dictadura les gritó: "cómanse las vacas", y el propio Domingo Durán Newmann, casi símbolo emblemático de los agricultores pinochetistas del sur, fue enviado a un exilio que vivió en Bariloche. Estos hechos condujeron a que en un momento se dijera que el mayor latifundista de Chile era el Banco de Chile. La pulverización de la propiedad se acentuó por estos complejos motivos propios de una transición como la que acá estamos analizando.

El campesinado alzado y luego el que no se había alzado también fueron expulsados de las haciendas que aún quedaban, de los antiguos asentamientos campesinos de la Reforma Agraria, y pasaron a formar una enorme masa laboral desperdigada en poblaciones rurales, cerca de los "frentes de trabajo"; era una masa de trabajadores pauperizados ávida de obtener cualquier tipo de ocupación. Podemos calcular que en el sector reformado había aproximadamente 120 mil trabajadores, los que con sus familias a lo menos nos da una cifra aproximada de medio millón de personas o más. A ello se agrega la expulsión casi inmediata de todo el personal permanente de fundos y haciendas. 30 mil de estas familias, las más numerosas ya que tenían mayor puntaje, recibieron parcelas y dos tercios de ellas las vendieron casi de inmediato; el programa de "Casa y Goce" instaló en el campo a unas 15 mil familias más. En resumen podemos calcular que casi un millón de personas pasó de habitar en el sistema hacendal directo, por lo general al interior de los fundos, a vivir en pequeños pueblos, villorrios, caseríos, en fin, nuevos espacios deteriorados de vida en el campo, con todas las consecuencias de ello.

En dos palabras: la rigidez de los factores productivos agrícolas, que ha sido siempre el escollo para el funcionamiento pleno del capitalismo agrario, se desplomó. Quedaron libres en el mercado más de 10 millones de hectáreas de tierras de todos los tamaños, calidades y precios. Junto a ello casi un millón de personas a disposición de un mercado absolutamente desregulado; mano de obra abundante y bien localizada; organización social (vgr. sindicatos) reprimida e incluso inexistente en el medio rural; mercados internacionales emergentes en un periodo de re globalización de la economía mundial; largo periodo de inversión en tecnología a cargo del Estado chileno y que es apropiada gratuitamente por los nuevos empresarios que ante estas circunstancias ingresan al negocio agrícola; y sobre todo, capitales bancarios y financieros a disposición, en medio de una debacle del capitalismo industrial y urbano por la aplicación del modelo ultra neoliberal de los llamados "Chicago Boys". En ese contexto surge un nuevo empresariado agrícola que reniega del rentismo hacendal y va creando una cultura 
o mentalidad en que el riesgo capitalista, la innovación tecnológica, la producción creativa son valorados y fuentes de prestigio ${ }^{2}$.

\section{LA ACUMULACIÓN ORIGINARIA A LA CHILENA}

Va a ser la década del setenta y ochenta un periodo clásico de "acumulación originaria", en que se expropió al campesinado de sus medios de producción, que aunque precarios, ya que era en tierras de haciendas, era enorme; se revolvió y fragmentó la propiedad agrícola, el precio de la tierra en un momento se desplomó y se establecieron los grandes predios forestales que arrasaron con la propiedad campesina y que contaron con un apoyo indecente del Estado Militar. Vale la pena leer las primeras líneas de afamado capítulo 24 de El Capital:

"Esta acumulación originaria viene a desempeñar en la Economía política más o menos el mismo papel que desempeña en la teología el pecado original. Adán mordió la manzana y con ello el pecado se extendió a toda la bumanidad. Los origenes de la primitiva acumulación pretenden explicarse relatándolos como una anécdota del pasado. En tiempos muy remotos se nos dice-, habia, de una parte, una élite trabajadora, inteligente y sobre todo ahorrativa, y de la otra, un tropel de descamisados, haraganes, que derrochaban cuanto tenian y aún más. Es cierto que la leyenda del pecado original teológico nos dice cómo el hombre fue condenado a ganar el pan con el sudor de su rostro; pero la historia del pecado original económico nos revela por qué hay gente que no necesita sudar para comer. No importa. Así se explica que mientras los primeros acumulaban riqueza, los segundos acabaron por no tener ya nada que vender más que su pellejo. De este pecado original arranca la pobreza de la gran masa que todavia hoy, a pesar de lo mucho que trabaja, no tiene nada que vender más que a si misma y la riqueza de los pocos, riqueza que no cesa de crecer, aunque ya baga muchisimo tiempo que sus propietarios han dejado de trabajar". (Carlos Marx. El Capital. Tomo I. Traducción de Wenceslao Roces. Fondo de Cultura Económica. Capitulo 24. Pp 102)

2. Quiénes forman en términos sociológicos esta nueva capa de medianos empresarios es otro asunto muy poco estudiado. En muchos casos son los hijos de los antiguos hacendados, pero hay muchos sectores de clase media de carácter regional que ingresan a las actividades agrícolas. La hipótesis de que la fragmentación de la propiedad rural fue deliberadamente deseada por un sector militar/policial para que fuese posible de ser adquirida por sectores que habían luchado contra Allende (camioneros, comerciantes, autobuseros, etc...), no es descabellada. Lo concreto es que una nueva camada empresarial intentó hacerse del campo; muchos de ellos fracasaron y ahí comenzó, años después, un proceso de reorganización y concentración de tierras del cual aún no tenemos datos fidedignos. 
Es el pecado original del capitalismo agrario chileno y quizás de todo el capitalismo triunfante de las últimas décadas. En una entrevista que hice hace años a Fernando Léniz, en ese entonces Presidente de la Corma, Corporación de la Madera, y en algún momento ministro de Pinochet, me relató cómo se le había planteado al gobierno resolver la cesantía gigantesca con el Plan de Empleo Mínimo (PEM), y el Decreto Ley 701 de reforestación del país en los años setenta. Tres millones de hectáreas salieron a remate y fueron adquiridas a vil precio por un puñado de empresas a las que además se les habían traspasado las fábricas estatales de celulosa. Se remataron las tierras y las adquirieron en cantidades incalculables. La Corporación Nacional Forestal, que estaba al mando de Ponce Lerou, yerno del dictador, les entregaba gratuitamente las plantas de pino insigne, les subvencionaba los árboles cuando prendían, y el PEM le pagaba la mano de obra. Tenemos relatos de masas de trabajadores de la zona de Arauco, muchos ex mineros, que eran subidos a camiones militares y llevados a la Cordillera de Nahuelbuta a plantar pinos. Las consecuencias de esta "acumulación originaria" han sido y son enormes. Estas empresas destruyeron el mundo rural transformándolo en un "desierto verde", despoblaron regiones enteras y las llenaron de poblaciones callampas, como se puede ver en los cerros de Constitución. Cercaron a las comunidades mapuches de bosques que secaron las vertientes y son la causa, no la única pero sí la de mayor importancia, de la existencia de una tercera guerra de Arauco en el sur de Chile. Estas empresas se transformaron en las bases de grandes conglomerados financieros y se llevan los recursos invirtiendo en el extranjero sin que nadie les ponga atajo; estas empresas, dado su origen vandálico, no tienen ningún cuidado con lo que hacen, dónde plantan sus bosques, y sólo buscan aumentar la tasa de ganancia provocando desastres ecológicos gigantescos y en este verano pasado (2017) el mayor incendio forestal de nuestra historia. Pero como señala Marx en la cita, nadie se recuerda del pecado original: asesinato y desapariciones de campesinos, liquidación de los sindicatos, expulsión del campesinado, apropiación indebida de tierras, etc...

Fue la acumulación originaria a la chilena. De ese "pecado original" no hay memoria, como señalaba hace 150 años el barbudo profeta; nadie se acuerda de los caídos y el capital se viste una vez más de levita y sombrero de copa, desempolvando falsos abolengos.

\section{CONSOLIDACIÓN DEL SISTEMA AGRO EXPORTADOR}

Luego, en la década del noventa viene el periodo de estabilización de esa estructura productiva y su consolidación hasta el día de hoy. Los factores productivos estaban disponibles y de manera absolutamente libre. Recordemos que en el año 1990 los 
profesores de Economía de la Universidad Católica (Arístides Torche y equipo) establecieron que en Chile había cinco millones de pobres, esto es, la mitad de la población. Por tanto, faltaba que los mercados se ampliaran, para lo cual el salto de la globalización /mundialización como consecuencia de la caída del bloque soviético, la apertura asiática, etc...hizo lo suyo. El impulso de los tratados de libre comercio en la década del noventa permitió que el sistema ya instalado se oxigenara, diera saltos gigantescos y las exportaciones se multiplicaran como nunca en la historia de Chile. Finalmente, la crisis agro alimentaria mundial de fines de los noventa vino a dar un nuevo impulso al "sobre" capitalismo agrario, provocando un salto inimaginable de productividad ${ }^{3}$. El trigo, por ejemplo, pasó de modestos promedios de quintales por hectárea a sobre cien en los últimos quince años. La revolución verde llegó tardíamente al país y permitió un nuevo impulso productivo a una estructura ya en ese momento establecida.

El Estado jugó un papel central en este proceso. Un largo tiempo de programas tecnológicos como el Plan Frutícola de la Corfo, programas de adaptación de semillas y frutos del campo del Instituto Nacional de Investigaciones Agropecuarias y una política de sanidad vegetal y animal llevada a cabo con dedicación por décadas permitieron que fuera posible el salto al "sobre" capitalismo. El caso de la eliminación de la fiebre aftosa es paradigmático. Ese enorme bagaje tecnológico ha sido apropiado por los privados de modo gratuito, convirtiéndose en una suerte de subsidio gigantesco a la acumulación del capital agrícola, a las empresas agropecuarias que siguen sin pagar impuestos reales, sino solamente rentas presuntas.

El eje productivo de la nueva estructura de tenencia de la tierra es la mediana propiedad que, en términos generales, en la zona central produce frutas y viñedos y en el sur ganadería, trigo, avena y otros cereales. Cordones de pequeña propiedad productiva se han consolidado alrededor de las grandes ciudades, abasteciendo de hortalizas a los mercados urbanos. Sistemas de integración vertical entre agro industrias y pequeña propiedad se han consolidado al igual que cadenas productivas entre pequeños productores y agro negocios e incluso cadenas de supermercados. Un 70\% de la producción de hortalizas se comercializa a través de las "ferias libres"

3. Es poco estudiado y conocido el efecto que produjo en Chile la crisis alimentaria. Esta se produjo por una sobre especulación en el precio de los alimentos, en particular por la derivación de grandes volúmenes de cereales a la industria de los biocombustibles. El alza de precios en los alimentos condujo en la mayor parte de los países, sobre todo en África, a enormes hambrunas; en cambio, en Chile condujo a cambios tecnológicos, aumentos de productividad y extensión de cultivos. 
de las ciudades, en que la dispersión de la propiedad es muy alta, no así el control del comercio mayorista. Igualmente se consolidó el sistema forestal con millones de hectáreas concentradas en la propiedad de un puñado de cinco empresas que unen esa actividad con la de la celulosa.

Un fenómeno central del periodo ha sido la concentración y especialización regional de las producciones agropecuarias y forestales. La hacienda tradicional por definición era multiproductiva, en cambio las empresas son actualmente mono productoras. De la zona central, donde está Santiago, la capital de Chile, se ha desplazado casi totalmente la ganadería al sur del país, los cultivos de cereales y, por cierto, los bosques y la actividad forestal. Los fértiles y estrechos valles del centro del país se especializan en producción de frutas y vinos de exportación. La balanza comercial agrícola señala un aumento vertiginoso de las exportaciones horto frutícola, de carnes y diversos productos que según los ciclos se ponen en boga como son hoy día los berries, arándanos y pequeños frutales altamente valorizados en el mercado internacional. El año pasado las exportaciones de cerezas a China se han transformado en la "guinda de la torta" del neo capitalismo chileno.

La agricultura chilena es un caso de éxito capitalista clásico. En el Manifiesto Comunista Carlos Marx señala claramente que lo que el capitalismo logra es un aumento gigantesco de la producción, pero "alprecio de un sistema en el cual una categoría de seres humanos, los dueños del capital (la burguesía), explota a otro sector, los trabajadores. El comportamiento de los empresarios está marcado no por la 'rapacidad' sino por la competencia, que lo exige. El sistema funciona de esta manera”.

\section{LAS CONTRADICCIONES SOCIO CULTURALES DEL "SOBRE" CAPITALISMO}

La Reforma Agraria provocó enormes cambios en la sociedad chilena en su conjunto. Veamos algunos.

Se rompió la relación entre lo urbano y lo rural en la medida en que lo rural se transformó casi exclusivamente en agrícola. El campo dejó de ser un lugar donde había un "modo de vida" y se reemplazó por un espacio para hacer negocios, plantar árboles y arbustos sin consideración de la vida rural, del ambiente rural y, por el contrario, por lo general en contra de la ruralidad. Esto es, se transformó el antiguo espacio rural en un espacio extractivista, una extensión indiferenciada y perversa de lo urbano.

La mayor parte de los conflictos que hay hoy día en Chile tienen esta matriz: defensa de lo rural frente a lo agro extractivo. El caso de los cerdos de Freirina grafica bien lo 
que acá se afirma ${ }^{4}$ La crianza familiar de cerdos, característica casi simbólica de lo rural, el "chanchito" donde se guardan los ahorros, es reemplazada por una fábrica que puede estar localizada en cualquier parte y hace pedazos los retazos de ruralidad existentes, y provoca externalidades incalculables. Una buena idea, un "nicho" de exportaciones en países de alta demanda de carne de cerdo, es desaprovechada en un esquema de expansión democrática y campesina rural y entregada a un monopolio de extrema concentración. Las exportaciones de cerdos, si hubieran podido ser realizadas por miles de miles de campesinos, organizados en cooperativas, por ejemplo (como fueron las cooperativas campesinas de la comuna de Navidad, y tantas otras hoy destruidas), no sólo habrían permitido democratizar las ganancias, sino profundizar el mundo rural. Es por ello que hablamos de "sobre" capitalismo, ya que cualquier iniciativa, incluyendo las de buena fe que organizan los agentes del Estado, se transforma en un negocio avasallador sin control, ni voluntad tampoco o capacidad de control por parte del Estado.

En segundo lugar, el campesinado en su gran mayoría dejó de serlo y pasó a ser una categoría semejante a la de "pobladores" de villorrios, pueblos y ciudades ubicadas en antiguos territorios rurales. Porque cambió la geografía sobre todo en la zona central. Durante la contrarreforma agraria, como se ha dicho, miles de miles de campesinos dejaron de serlo. Durante la dictadura, en plena acumulación originaria, se llenó la zona central de poblaciones callampas en rincones cercanos a los frentes de trabajo. Después del año '90 la Concertación consolidó mediante programas de vivienda estos poblados. Donde antes había una hacienda hay ahora diversas poblaciones, verdaderos "dormideros de mano de obra", que en algunos casos llevan el antiguo nombre. Allí se ven sobre los techos las antenas de televisión y las parabólicas que adormecen las conciencias de los trabajadores de temporada que llegan después de largas jornadas a sentarse a ver lo que le ocurrió a Moisés o a algún barbudo jeque turco de la actual Turquía en soporíferas telenovelas.

4. La empresa Agrosuper instaló en la localidad de Freirina, en el norte del país, un enorme establecimiento de producción de cerdos, principalmente para la exportación. Se trata de miles y miles de animales, 480 mil cerdos fueron sacrificados según la prensa, inimaginables para mentalidades medianamente normales, que están encerrados en jaulas, comen, crecen, engordan, son sacrificados, enfriados o congelados en sus partes y enviados a mercados de Estados Unidos y Europa. Es una raza de cerdos especialmente modificada que tiene poca grasa. Freirina es un pequeño pueblo con muy pocos habitantes. Muchos de ellos trabajaron en esa empresa y vieron allí una oportunidad. El criadero provocó un desastre ambiental, contaminando las pocas aguas existentes, el aire con un mal olor que impedía la vida misma, etc. Después de grandes movilizaciones se decretó el cierre de la "fábrica de chanchos". El patriarca de la firma Agrosuper, Gonzalo Vial, declaró hace poco que fue el error más grande de su vida empresarial comercial, ya que lastimó la "marca". 
Se calcula en el último censo agropecuario del 2007 que existen casi 500 mil personas que trabajan en las temporadas agrícolas y que por ello mismo, como son muchas mujeres, se les denomina "temporeras". Su lugar de habitación es semi urbano y urbano, viviendo en esos villorrios rurales, caseríos construidos por el Estado cercanos a los huertos, y para el periodo de cosechas viajando a veces de lejanos lugares. La población indígena mapuche suele salir de sus campos, minifundios, a cosechar en los veranos la fruta. Cada año, por otra parte, llegan a las cosechas masas de mano de obra extranjera, sobre todo de Perú, Ecuador, Colombia y más recientemente, Haití. Algunas proyecciones señalan que al ritmo de las nuevas plantaciones de vides y frutales, en pocos años más del 50\% de la mano de obra será producto de migraciones internacionales. No son pocos quienes abogan por cambios legislativos de modo que se pueda aumentar la presencia de estas personas, hoy limitada a un porcentaje de la faena, de modo de abaratar aún más la mano de obra agrícola. El bullado caso de los trabajadores y trabajadoras paraguayas contratados por el señor Francisco Javier Errázuriz, ex candidato a la Presidencia de la República, es una expresión de ello ${ }^{5}$.

La casi total ausencia de organización campesina y sindical conspira sobre una mínima y racional regulación de la mano de obra, de sus contratos y remuneraciones. En cada campaña electoral presidencial los candidatos prometen legislar a favor de este sector enorme de personas, que luego es olvidado dada la enorme presión de los intereses en juego.

En tercer lugar, hay que recordar que la hacienda y la Iglesia eran primas hermanas o simplemente hermanas gemelas. La destrucción de la primera llevó a la indeclinable y estrepitosa caída de la otra. Es por ello que abundan los "ministerios" evangélicos. En el antiguo mundo rural se reproducen sectas de toda naturaleza que cumplen quizás con igual fuerza que la Iglesia, un rol apaciguador. La secularización de las nuevas generaciones es un cambio radical.

En cuarto lugar, esta ruptura de los lazos urbano rurales ha tenido una consecuencia derivada de los cambios anteriores, que es la autonomía de las culturas urbanas. Me explico. Las ciudades chilenas tuvieron desde siempre una impronta y una cultura

5. El empresario, ex senador, ex candidato a la Presidencia de la República, Francisco Javier Errázuriz, ha ido adquiriendo, de diversas formas y con diversos métodos grandes propiedades de la antigua provincia de Colchagua, que en algún momento fue mayoritariamente de su familia. Él ha señalado una suerte de misión en función de volver a esa situación de extremo propietarismo. Ante la falta de mano de obra contrató a través de subcontratistas a trabajadores del Paraguay. Fue denunciado por tenerlos en una cuasi esclavitud y en condiciones indignas. http:/ / www.latercera.com/noticia/francisco-javier-errazuriz-debera-pagar-122-millones-portrafico-de-trabajadores-paraguayos/ 
rural y sobre todo "campesina". Los modelos de familia rural se habían trasladado a las ciudades. Esta ruptura tiene varias consecuencias. La primera: las clases altas y las medias arribistas suspiran y añoran la ruralidad perdida. Techan sus casas con tejas de barro, o tratan de hacerlo, enrejan sus jardines como si fuesen liliputenses parques de haciendas, celebran sus matrimonios en antiguas casas de campo, tienen caballos de raza chilena, van a los rodeos disfrazados de huasos con costosas mantas, y en vez de chicha baya y curadora, brindan con champán. La ruralidad de las clases altas quedó suspendida en una suerte de nostalgia conservadora.

Pero de manera mucho más profunda, las clases altas tradicionales perdieron el modelo de dominación / subordinación al cual se habían acostumbrado a lo largo de los siglos. El llamado "respeto" de los inquilinos a sus patrones, el sacarse el sombrero frente a ellos, se rompió indeclinablemente. El trato entre las clases sociales es uno de los aspectos más complejos de la vida en común. ¿Cómo se trata de buena manera a un trabajador? El modelo chileno fue siempre el hacendal. Una mirada de arriba a abajo, pero cariñosa. "Mire, mijo, vaya a buscarme los bueyes". Una mirada de abajo hacia arriba, de aparente respeto: "Mande, su merced". De una u otra manera ese modo de convivir se reproducía en el empleo doméstico, en los talleres y pequeñas actividades, en los restoranes y lugares públicos; en fin, era el ensamblaje de la vida social íntima de este país. A partir de la Reforma Agraria este aspecto tan determinante de la vida social se rompió. Comenzó una suerte de transición, al igual que en la economía, que nadie sabe muy bien a dónde conduce. Los antiguos siervos se convirtieron en clientes y se saltaron el periodo de ser ciudadanos, sin que nadie se diera mucha cuenta. Las consecuencias son extremadamente brutales para quienes han vivido los momentos hacendales de dominación y subordinación, tanto en el punto alto de la escala social como en los más bajos.

Las consecuencias a nivel socio político y cultural en las clases altas son profundas. Antes de la Reforma Agraria las clases hacendales y sus adláteres eran católicas, hoy día pertenecen a sectas adosadas de mala manera a la Iglesia Católica. Los empresarios actuales son Opus Dei, Legionarios de Cristo, Soldadicios y miembros de sectas deleznables como los de la Iglesia del Bosque del cura Karadima, preso por violar jóvenes y multitud de otros "pecados capitales".

En términos de vida cotidiana, las clases altas se han refugiado en "los faldeos cordilleranos" ${ }^{36}$, aterrados por la amenaza de la delincuencia que aparentemente los

6. Comunas de Vitacura, Las Condes, La Reina, Barnechea, etc., bastiones políticos de la derecha. Se repite en menor medida en algunas ciudades "de provincias", como Viña del Mar, en que se han subido a los cerros de Reñaca y Con Con, y en mucha menor medida Concepción y Temuco. Suelen ser "guettos acosados" por la delincuencia, encerrados por rejas, y en los últimos años sobre vigilados por drones. 
acosa. Van a colegios de sus propias sectas, a universidades privadísimas y por cierto de "buena calidad" según los parámetros vigentes e internacionalmente aceptados, y luego trabajan en el sector financiero, agropecuario, y exportador. La agresividad comercial de este sector es sin duda muy impresionante. En Perú, por ejemplo, han logrado instalar el "modo de vida chilensis", construyendo grandes sistemas de mercados llamados "malls", empresas de todo tipo, y las más increíbles producciones agrícolas con el método conocido como "land graving" o acaparamiento de tierras. Enormes plantaciones de papas en terrenos anteriormente desérticos de la costa, espárragos de exportación en los valles de manera previa a la reforma agraria peruana; en fin, una capacidad empresarial no conocida anteriormente y producto de esta densidad cultural de un grupo social acorralado que no confía de ninguna manera en las alianzas tradicionales con los sectores populares.

Por su parte, las clases populares ya no conocen lo rural ni lo recuerdan más que en la ansiedad sub consciente de comer grandes asados, parrilladas futboleras que nublan de humo el paisaje de las ciudades. Quedó en el inconsciente popular el campo como un lugar de promisión frente a la violencia urbana, a la inestabilidad permanente, a la dependencia salarial sin alternativas. Por primera vez, quizás, hay una juventud netamente urbana, que se expresa con el desenfado de no tener recuerdos de lealtad con los patronos, ni siquiera con los modos de la subordinación tradicional chilena. Junto con sus expresiones desenfadadas son indomables y rechazados y no comprendidos por los esquemas marcados por el modo chileno de la dominación social, como delincuentes, flaites, etc... En las tres ciudades más importantes de Chile el porcentaje de jóvenes que NI trabaja, NI estudia, los "Ninis", es uno de los más altos de América Latina, lo que puede ser interpretado como un enorme proceso de características anómicas, muy semejante al ocurrido en los clásicos procesos de transición de estructuras semi capitalistas o feudales al capitalismo. Recordemos solamente que las teorías clásicas señalan que fueron las guerras, la formación de los ejércitos, lo que posibilitó en palabras de Marx la "civilización de la clase obrera", esto es, transformar a las clases no capitalistas en clases obreras disciplinadas. Esto no ha ocurrido en Chile y las consecuencias sociales y económicas son enormes ${ }^{7}$.

Resumiendo, podríamos decir que la Reforma Agraria rompió los lazos de dominación y subordinación tradicionales que se habían construido a través de siglos

7. Radrigán y Barrales, dos de los grandes escritores de teatro contemporáneo chileno, quizás exploraron ese aspecto brutal de la insubordinación de las clases populares post Reforma Agraria y post dictadura. Ver por ejemplo el libreto de Barrales denominado Las niñas araña, que cuenta la historia real de unas niñas que se subían por los edificios del barrio alto para robar en los departamentos. 
en las haciendas y que de una u otra manera se habían expandido a las ciudades, al empleo fabril (piénsese en la Papelera y numerosas industrias que tenían poblaciones para sus obreros), al empleo doméstico, por supuesto, y al conjunto de clientelas políticas. Estos lazos, que son vistos como de "respeto" por las antiguas clases adineradas y oligárquicas, se han roto junto a los sistemas productivos. Sin querer extremar el argumento, no cabe mucha duda de que la desconfianza, la ruptura de los lazos comunitarios, la sospecha y descrédito de las instituciones, la ausencia de liderazgos tradicionales, se pueden analizar a través del paso rápido y reciente del régimen de la servidumbre a un régimen en que el trabajo percibe que se está en procesos de acumulación originaria de capital, concentración gigantesca de los mismos, transnacionalización acelerada; en fin, fractura con los códigos conocidos de los sistemas de subordinación y dominación en Chile.

Estas transformaciones, uniéndose a conocidos procesos globales y globalizados, han tenido consecuencias enormes en el plano de la moral y la decencia. Los códigos de la convivencia chilena fueron fundamentalmente rurales hasta las generaciones anteriores; estaban impregnados de "presencialidad", para usar un concepto conocido. Esto es, de relaciones cara a cara, comunitarismo, ("somos una familia", le repetían una y mil veces los hacendados a sus inquilinos), concepto de "honor" ligado al valor de la palabra otorgada, liderazgos tradicionales, masculinos y autoritarios; en fin, un conjunto no escrito de conductas que tenía su base en las profundidades de la historia rural de Chile. La ruptura de estas relaciones fundantes y la ausencia de reemplazo por otras de carácter moderno (la "modernidad abortada") es una fuente de inspiración para el robo de cuello blanco, la colusión de empresarios anteriormente afamados por su auto convicción de prestigio, abolengo y decencia, el soborno en gran escala que reemplaza al pequeño cohecho rural en que se mataba un animal para que los inquilinos fuesen a votar, la capacidad de esconder los capitales en paraísos fiscales, en vez del modelo de doña Juana Ross de Edwards de repartirlo, algo que sea, entre los pobres. En fin, la enorme desconfianza que se produce en una sociedad que ha perdido en sus élites el sentido de la decencia. Es el gran cambio del reemplazo de una clase alta marcada por un código rural de dominación a una escondida en los faldeos cordilleranos, que va a sus propios colegios y universidades, y que se reúne en sectas poco dignas o simplemente delictuales y comulga los domingos en público para demostrar que está libre de pecado, del pecado original del que hemos hablado. Porque las vías del desarrollo capitalista tuvieron a lo menos dos elementos, el cambio de los sistemas de producción y el cambio de una clase feudal en burguesa; y ello no ha ocurrido aún en Chile. La clase alta chilena es liberal en lo económico y conservadora/ reaccionaria en lo social, cultural y político, como lo han demostrado tantos estudios y se lo ve cotidianamente. La modernidad en Chile sufrió de aborto por múltiples causales. 
La cultura liberal que acompañó en otras latitudes al capitalismo surgente no existe, ya sea porque los tiempos son otros o por el porfiado sistema elitista criollo. Se produjo, por tanto, una contradicción entre un sistema productivo en que la ganancia y la sobre explotación de los recursos humanos y naturales es excesiva, y una clase empresarial contaminada de una cultura reaccionaria, conservadora y nostálgica del poder perdido. En esa contradicción no es inexplicable que surja el oportunismo más desenfrenado, el aventurerismo, se instale la corrupción y se produzca una fuerte crisis de gobernabilidad y dominación.

\section{DEL "SOBRE” CAPITALISMO Y SUS CONTRADICCIONES}

Carlos Marx pareció salir de las librerías con la caída del Muro de Berlín y el desplome del mundo socialista a la soviética, sin embargo, como señala Slavoj Zizek, "la mundialización (globalización) y sus excesos le han dado una segunda vida a las ideas políticas de Marx”. Y "qué duda cabe”. Las grandes predicciones del filósofo alemán se reproducen de una manera siniestra, esperpéntica quizás, a nivel global. Miles o millones de seres humanos pauperizados hasta lo imposible se suben a barcazas o "pateras" atacando la riqueza soberbia de los países ricos europeos; miles de jóvenes humillados y desesperados por la miseria se suben a los trenes a cambio de dar dinero a las maras para llegar de la manera más peligrosa al paraíso norteamericano. Marx no se imaginó nunca que un millonario a cargo del Estado más poderoso del mundo, que para Marx era el consejo de los empresarios y burgueses simplemente, iba a construir una muralla entre los ex trabajadores pauperizados y el paraíso del dólar. De cada avión que llega de Puerto Príncipe al aeropuerto Comodoro Merino Benítez, ex Pudahuel, de Santiago de Chile, son devueltos un 10\%, alrededor de unos 10 a 15 al día. No mueren en el mar de las Islas Canarias, pero cualquiera puede imaginar la muerte psicológica y humana de cada uno de esos trabajadores que a lo único que aspiraban era a sacar las uvas del valle central de Chile que se convierten en los vinos premium que le dan prestigio mundial a este país. La profecía marxista acerca de la concentración creciente de la riqueza y la pauperización de las masas quizás no se dio "en un solo país", sino a nivel global y ese constituye el marco analítico adecuado para el análisis del "sobre" capitalismo del que nuestro país es un ejemplo paradigmático.

Ocupamos el neologismo de "sobre" capitalismo para señalar un particular momento que se vive a nivel mundial en el que juegan simultáneamente fenómenos "out door", esto es, globales o que ocurren muy lejos del lugar o localidad rural, y fenómenos "in door" (Giddens) que se producen en el mundo local, sobre todo en las sociedades campesinas. Estas situaciones son hoy día de una importancia 
enorme en el ámbito de la agricultura y el mundo rural. Son cadenas, a veces oscuras y misteriosas, que se entrelazan entre lo global y lo local, como lo han señalado numerosos autores. Por cierto que en muchos casos la destrucción de la producción campesina es la consecuencia evidente.

Aunque la destrucción de los sistemas de producción domésticos, la formación de cadenas agro alimentarias mundializadas y los efectos del comercio internacional no son asuntos nuevos, en algunos casos observamos una tal exacerbación de ellos que no podemos menos que catalogarlos como algo diferente. Asuntos como el "land graving" o acaparamiento de tierras, saltos insólitos en la productividad, nuevos productos en el comercio internacional globalizado, consecuencias ambientales desastrosas, movimientos migratorios masivos de mano de obra, condiciones de trabajo cada vez más deterioradas, en fin, son fenómenos que bien merecen ser señalados usando un neologismo como el de "sobre" capitalismo.

En Chile se dan estos fenómenos de un modo quizás emblemático. Nuestro interés es llamar la atención del lector acerca del modo como se reúnen en un mismo sistema agroalimentario elementos propios de una globalización cada vez más agresiva, a gran escala y sin limitaciones, elementos producto de las consecuencias de tratados de libre comercio, en el caso de Chile muy abiertos y generosos con el capital internacional: y aumentos de productividad, sanidad animal, control de plagas, etc..., y sus consecuencias sobre procesos de concentración de capital, descampesinización y también reforzamiento de las condiciones de trabajo campesinas que podemos incluso nominar como "re campesinización", y desastres medio ambientales, como por ejemplo ocurre con la escasez de agua.

Nombrar a estos procesos como "sobre" capitalismo tiene dos sentidos. El primero, que hay formas mucho más "suaves", por decirlo de alguna manera, del ejercicio capitalista, en las que el Estado tiene mucho más que decir, controlar, y los trabajadores mucho más que participar, mejores sueldos y condiciones de trabajo, en fin, relaciones mucho más democráticas entre las personas y de mayor sustentabilidad entre la sociedad y el medio ambiente. Esto no es poco. En Chile el éxito del capitalismo ha estado y está en su carácter excesivo, en la forma a veces deshumanizada absoluta en que se ejerce el proceso de obtención de ganancias, en la ausencia de controles tanto en el ámbito medio ambiental como laboral.

Por ejemplo, habría que discutir en forma abierta los costos de la producción horto frutícola y el porcentaje que le corresponde a la mano de obra. Los empresarios señalan cifras por lo general poco transparentes, en las que se dice que el costo de la mano de obra apunta sobre el 50\% del costo total de la producción. Hay, sin embargo, estudios que al ver los precios que se pagan por el producto en los mercados internacionales y que le llegan al productor, evidencian que la mano de obra es un porcentaje muy bajo del costo. En los berries, que son un producto 
intensivo de mano de obra, el año pasado al precio que se les pagaba a los trabajadores por la caja correspondía a un dólar de un precio final de aproximadamente 10 dólares. El aumento de los salarios, que podría hacer ingresar a nuevos contingentes de trabajadores jóvenes en forma masiva a las cosechas de verano como ocurre en Europa, es absolutamente posible en términos de costos, pero imposible en términos ideológicos dado el nivel de las tasas de ganancia y el reaccionarismo de los empresarios en moderarla.

A modo de otro ejemplo, las mismas empresas productoras de salmones en Noruega y en Chile ocupan estándares diferenciados, densidades de carga totalmente desiguales, pago de la mano de obra y condiciones de trabajo inequívocamente diferentes: en fin, uso de controles biológicos, medicamentos, antibióticos, etc. Lo mismo ocurre con los productores de mariscos en Galicia, España, y en Chiloé, que son de la mismas firmas, pero donde ellos mismos reconocen las diferentes maneras de producir y, por tanto, las sobre ganancias fruto de las mejores condiciones de explotación. Por el otro lado, por ejemplo, la competitividad hortícola, acuícola y minera del Perú se basa en el menor nivel de restricciones medio ambientales, en el menor precio de la mano de obra, y son las mismas empresas chilenas las que migran a esos "paraísos extractivistas". Un ejemplo que hemos estudiado es el del ostión de Tongoy. Las mismas empresas, los mismos técnicos, la misma tecnología migró al Perú, dado que el costo de mano de obra era sustantivamente menor. "El capital no tiene patria” profetizó el sabio alemán.

La segunda ventaja o derivada que hace útil el concepto de sobre capitalismo es la comprensión de que existe un entrelazado de tal naturaleza que ante cualquier cambio que se quiera realizar surge la amenaza de su hecatombe. Lo artificial se transformó en "natural" y es totalmente comprendido como un fenómeno irreversible. Esta excrecencia ideológica ha logrado permear de manera completa el pensamiento de las élites y se ha hecho realidad; los países del Tercer Mundo o de América Latina que han osado transitar a formas diferenciadas de capitalismo han sido duramente sancionados internacionalmente y a nivel local se han producido gigantescos desastres. Como decía con sorna un viejo presidente de este país, "Cuando las cosas son asi es que no son de otra manera"

Las posibilidades de que en Chile se haya instalado un sistema productivo marcado por el "sobre capitalismo" no es producto de la casualidad, sino de los hechos que "shockearon" a esta sociedad (Naomi Klein), dejándola a disposición de los más audaces experimentos. El mundo rural, agrario y campesino es quizás el caso de mayor envergadura. Vale bien la pena de analizar el asunto al cumplirse los 50 años de la ley de Reforma Agraria. 


\section{“SOBRE” CAPITALISMO Y "SOBRE” CONSUMO}

Quienes observamos la sociedad chilena no podemos menos de asombrarnos por sus contradicciones. En este trabajo, obviamente audaz y preliminar, quisiéramos relacionar lo que ocurre con la producción agro ganadera en Chile, el consumo de las masas al que denominaremos también como "sobre" consumo, y la ansiedad que ello provoca en las personas y que finalmente repercute de una manera difícil de comprender en el conjunto de malestares que caracterizan a esta sociedad. La hipótesis es sencilla y se refiere al rápido, reciente y masivo consumismo alimentario de la sociedad chilena, propio de un conglomerado que ha pasado por situaciones muy difíciles de hambre, escasez y dolores adheridos a esa situación en años relativamente recientes. Al igual que las sociedades que salen de enormes guerras que las han privado de casi todo, la chilena se ha encontrado en menos de una generación con oportunidades alimentarias inesperadas y muchas veces, a pesar de su calidad, excesivas. Por ejemplo, la producción y consumo ganadero del país, esto es, lo que se produce en carnes y lo que se consume, que a la luz de las cifras es bastante impresionante. No es poco decir que Chile consume más carne que cualquier otro país de América Latina y que es el segundo consumidor de pan después de Alemania en el mundo. Las cifras y datos señalan que en Chile se come principalmente pan y carne, a pesar de lo que cada uno estime que es su personal experiencia. Y eso se refleja en la mayor enfermedad que sufre la población, que es el sobrepeso, con sus derivadas evidentes y mortandad por infartos, etc. Entender los asuntos públicos, y por qué no políticos, desde esta perspectiva material brutal a lo menos sirve para pensar. Desde esta perspectiva no cabe mucha duda de que la sociedad chilena está en una situación de transición quizá demasiado rápida entre un periodo marcado por la falta de acceso a alimentos y la abundancia de los mismos que ha ocurrido en las últimas dos décadas, con los desajustes de carácter cultural imaginables y sobre todo el encierro estrecho en los límites del consumo.

Diversas son las tendencias: la comida rural tradicional fue el poroto. En los últimos años el consumo de leguminosas va a la baja de manera abrupta, mostrando el cambio de costumbres alimentarias locales. Crece, en cambio, el fast food a un ritmo desbocado y caen los pescados y mariscos. Este año 2017 ha crecido la comida rápida en casi un 17\% respecto al año anterior, a pesar de las campañas e incluso restricciones legales. Se ponen de moda los programas de cocina y las costumbres cambian en las grandes ciudades con restoranes llenos de público insaciable. Probablemente estas tendencias no tengan nada que ver con la política y la cultura, pero quizá son extremadamente explicativas. Alimentación y salud se ponen en el centro de las preocupaciones de las personas, las privatizan, las ponen ansiosas y son fuente de enormes malestares. La transformación incompleta de 
lo rural en urbano, las transiciones inacabadas de las que acá hemos hablado, son fuente de comprensiones, misteriosas por cierto, de las ansiedades.

Es por ello que el estudio del mundo rural no hace más que sorprendernos por los cambios que están ocurriendo en el campo y en especial en la producción agrícola y ganadera. Algunos de estos cambios rompen los esquemas acostumbrados y provocan quizá sonrisas escépticas. Sin embargo, quienes estamos desde hace décadas acompañando al campesinado en sus vidas y luchas, no podemos menos que mirar con cuidado estas transformaciones en que ellos quedan muchas veces prisioneros o simplemente son destruidos.

La diferencia aparente, y solamente temporal, con el pensamiento "marxista de Marx" es que el pensador, y sobre todo el observador que era desde su escritorio del Museo Británico, consideraba y creía que esos campesinos antes y obreros después, pauperizados, se levantarían iracundos y harían la revolución comunista como casi la habían hecho el '48 y luego en la Comuna de París; la primera como tragedia y la segunda como comedia. Hoy no sabemos bien cómo van a ocurrir los próximos hechos. Pero el fenómeno de ruptura entre el capital y el trabajo, o el no trabajo, es cada día más radical. En Chile, en la cola del mundo, se reproducen estos fenómenos de un modo a veces surrealista. Y es por ello que hablamos osadamente de "sobre" capitalismo. 